\title{
Study of variations in the pelvicalyceal system of kidney and its clinical importance
}

\author{
PR Wadekar, ${ }^{1}$ SD Gangane ${ }^{2}$ \\ ${ }^{1}$ Assistant Professor, ${ }^{2}$ Professor and Head,Department of Anatomy, Government Medical College, \\ Maharashtra, India
}

\section{ABSTRACT \\ Objective}

The present study has been undertaken to study the variations in renal pelvicalyceal system, to compare them with previous studies and to find their clinical implications.

\section{Materials and Methods}

A total of 100 kidneys (from 50 cadavers) were included in this study. The following parameters were measured 1)Lower Infundibular length, 2)Infundibular Width - Lower Infundibular Width (LIW), Middle Infundibular Width (MIW), Upper Infundibular Width (UIW), 3)Number of minor calyces and 4)Number of major calyces.

\section{Results}

The obtained data showed that there were numerous variations not only in the numbers of calyces of kidneys but also in the infundibular length and width.

\section{Conclusion}

Developments in endourology, percutaneous nephrolithotomy and techniques for retrograde percutaneous nephrostomy have rekindled interest in the anatomy of the renal collecting system. To perform these procedures safely and efficiently it is essential to have a clear understanding of pelvicalyceal anatomy and its variations. Thus the in-depth knowledge of pelvicalyceal anatomy will be of immense value to the clinicians of related specialties.

\section{Key words: calyces, Infundibular length, infundibular width, pelvicalyceal system.}

\section{Introduction}

The variations of the renal collecting system and the developmental anomalies of kidney are numerous. The variations in the gross structure of the renal collecting system are probably as numerous as there are individuals and thus can be compared to fingerprints. The bilateral collecting systems present in any single

Correspondence: Dr. PR Wadekar

E-mail: drpankajwadekar@gmail.com individual are often similar but are rarely identical and not uncommonly, may be quite different even from one another.

Anatomy textbooks frequently divide calyces into major and minor components. The usual description states that three major calyceal systems arise from the renal pelvis, subdividing into three to five minor calyces. For 
Journal of College of Medical Sciences-Nepal, 2012, Vol-8, No-3

practical purpose all branches from the pelvis, whether single or multiple, are termed infundibula. ${ }^{1}$

The knowledge of detailed calyceal anatomy is very essential for endourological procedures, for the selection of the best method of kidney stone treatment for a specific patient, for the better understanding and interpretation of standard Intravenous Urography. ${ }^{2}$ The effect of pelvicalyceal anatomy on stone formation was not well evaluated up to date. If we consider that all the risk factors for stone formation are similar for both kidneys of a patient, it is very difficult to explain why a calculus is primarily formed in single calyx but not in other calyces of both kidneys, when metabolic factors are in operation. From this point of view, it is very logical to consider that different pelvicalyceal properties are the key factor for the lateralization of the stone and also constitute a risk factor for their etiology. ${ }^{3}$

The present study has been undertaken to study the variations in renal pelvicalyceal system, to compare them with previous studies and to find their clinical implications.

\section{Materials and methods}

A total of 100 kidneys (from 50 cadavers) were included in this study. In most of the previous studies Intravenous Urography (IVU) films were used for measuring the different parameters. In our present study the coronal section of each kidney was taken for measuring different parameters of the pelvicalyceal system.

The parameters measured were as follows

- Lower Infundibular length,

- Infundibular Width-
- Lower Infundibular Width (LIW),

- Middle Infundibular Width (MIW),

- Upper Infundibular Width (UIW),

- Number of minor calyces,

- Number of major calyces.

The parameters were measured as follows

\section{Lower Infundibular length (LIL)}

It was measured as a distance from the most distal point at the bottom of the lower calyx to the midpoint of lower lip of the renal pelvise as shown.

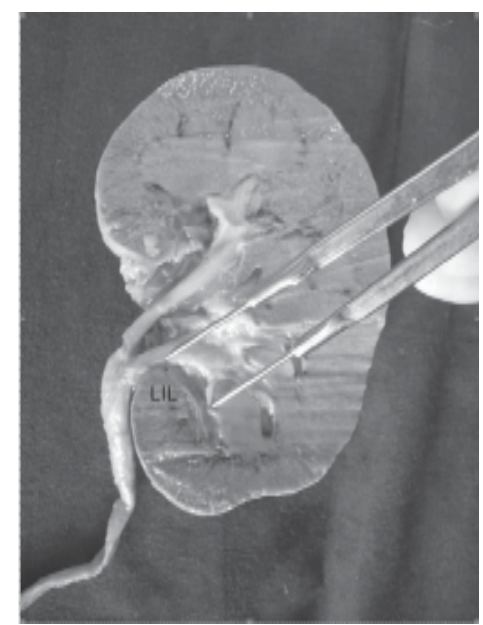

Figure 1: Measurement of LIL

\section{Infundibular Width}

LIW, MIW \& UIW were measured at the narrowest point along their respective infundibular axis.

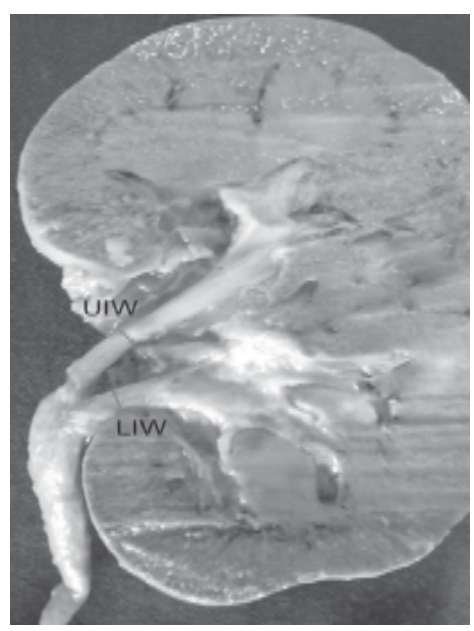

Figure 2: Measurement of UIW and LIw 
PR Wadekar et al. Study of variations in the pelvicalyceal system of kidney and its clinical importance.

Graph 1. Lower InfundibularLength

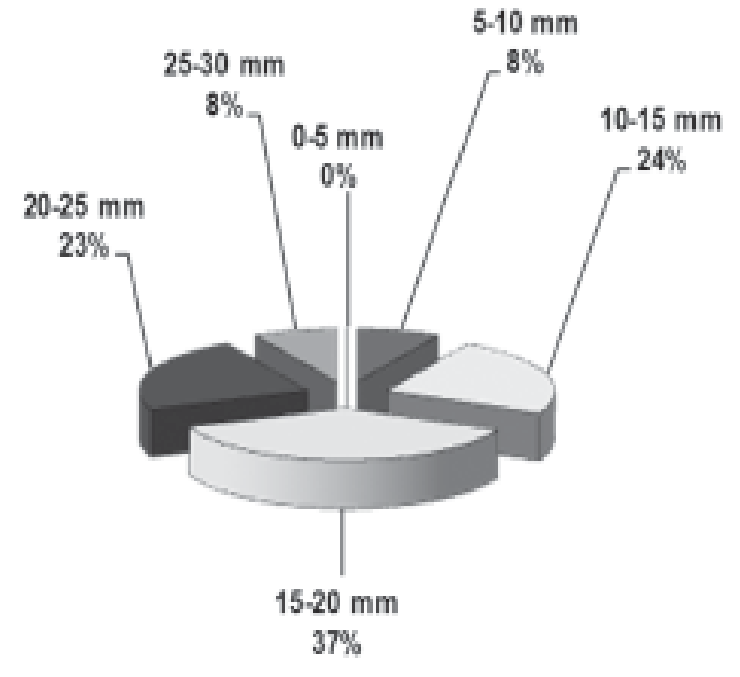

\section{Graph 2. Lower InfundibularWidth}

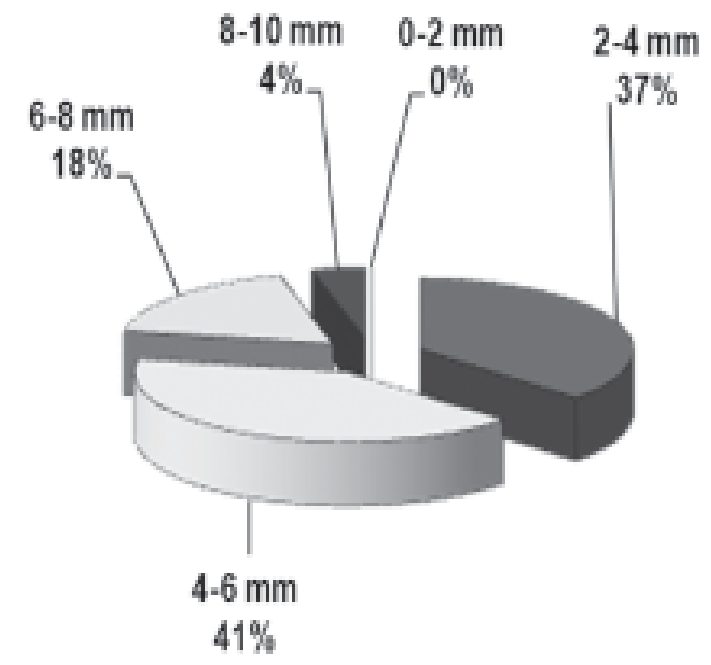

\section{Graph 3. Middle Infundibular Width}

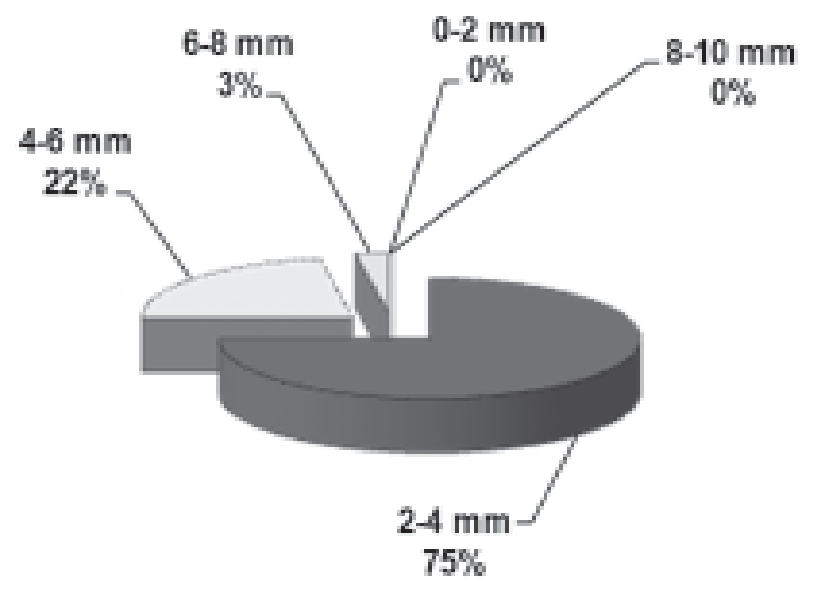

Graph 4. Upper Infundibular Width

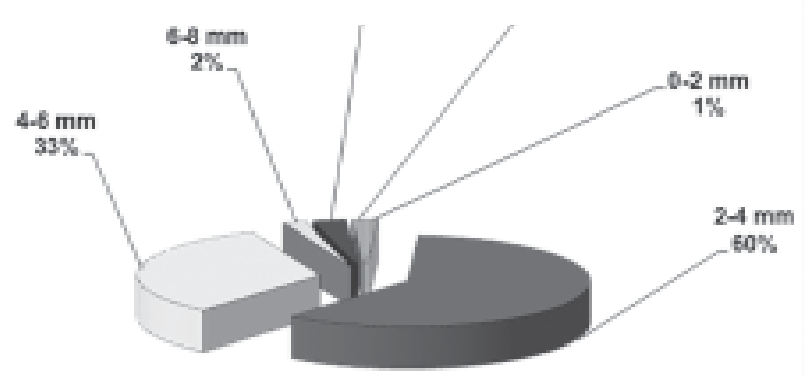

Graph 5. Minor calyces (in each kidney)

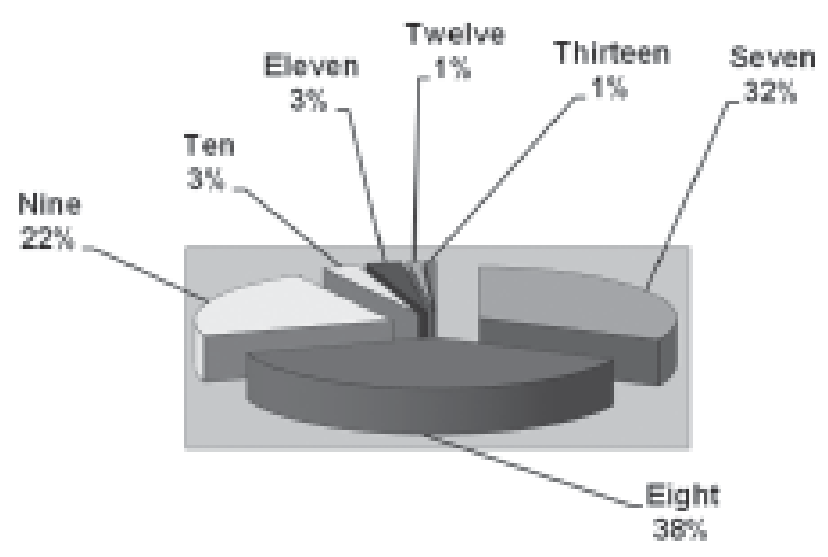

. Major calyces (in each kidney)

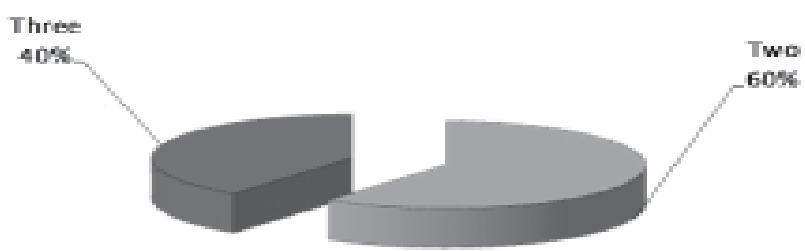

\section{Result}

A total of 100 kidneys (from 50 cadavers) were studied. The results of infundibular measurements and of calyces are shown in graph 1 to $6 \&$ and are discussed below.

\section{Discussion}

\section{Lower Infundibular Length (LIL)}

In our present study the LIL varies from $7 \mathrm{~mm}$ to 27.2 $\mathrm{mm}$ (the mean was $17.31 \mathrm{~mm}$ ) and it was $10-15 \mathrm{~mm}$ 
Journal of College of Medical Sciences-Nepal, 2012, Vol-8, No-3

in $24 \%$ and $15-20 \mathrm{~mm}$ in $37 \%$. (Graph no. 1). According to Sun Y. B. et al ${ }^{4}$ and Gupta N. P. et al ${ }^{5}$ the LIL was d" $30 \mathrm{~mm}$ in $60.87 \%$ \& in $77 \%$ respectively. In similar studies, Madbouly K. et a ${ }^{6}$ found that the LIL was d" $30 \mathrm{~mm}$ in 54.6\%. Srivastava A. et $\mathrm{al}^{7}$ found that in $54.55 \%$ the LIL was $<25 \mathrm{~mm}$. Another study was conducted by Sorensen C. M. et $\mathrm{al}^{8}$ where they found that LIL was $21-30 \mathrm{~mm}$ in $48 \%$, greater than $30 \mathrm{~mm}$ in $45 \%$.

\section{Lower Infundibular Width (LIW)}

In our present study the LIW varies from $2.2 \mathrm{~mm}$ to $9.7 \mathrm{~mm}$ (the mean was $4.72 \mathrm{~mm}$ ) and it was greater than $4 \mathrm{~mm}$ in 63\% (Graph no. 2). According to Sampaio F. J. B. et al ${ }^{9}$ and Li-ping Xie et $\mathrm{al}^{10}$ the LIW was greater than $4 \mathrm{~mm}$ in $60.3 \%$ and $67 \%$ respectively. Our present findings are comparable with these studies . Similarly, Gupta N. P. et al ${ }^{5}$ found that in $75 \%$ of cases the LIW was $5 \mathrm{~mm}$ or more and the mean LIW was $6.75 \mathrm{~mm}$. In similar studies, Sabnis R. B. et al ${ }^{11}$ found that the LIW varies from $2 \mathrm{~mm}$ to $16 \mathrm{~mm}$ with $73 \%$ having width of $>4 \mathrm{~mm}$. According to Madbouly K. et $\mathrm{al}^{6}$ and Srivastava A. et al $\mathrm{al}^{7}$ the LIW was $>5 \mathrm{~mm}$ in $41.7 \%$ \& $25.76 \%$ respectively.

\section{Middle Infundibular Width (MIW) and Upper Infundibular Width (UIW)}

In study conducted by Kupeli Bora et al ${ }^{3}$ the MIW varies from $1 \mathrm{~mm}$ to $10 \mathrm{~mm}$ (the mean was $2.71 \mathrm{~mm}$ ) and the UIW also varies from $1 \mathrm{~mm}$ to $10 \mathrm{~mm}$ (the mean was $3.01 \mathrm{~mm}$ ). In our present study the mean MIW was $3.65 \mathrm{~mm}$ \& it varies from $2.8 \mathrm{~mm}$ to 6.2 $\mathrm{mm}$ (Graph no. 3). The mean UIW was $3.80 \mathrm{~mm}$ \& it varies from $1.4 \mathrm{~mm}$ to $10.6 \mathrm{~mm}$ (Graph no. 4).

\section{Minor Calyces}

In present study the number of minor calyces varies from 5 to 11 and most often 8 minor calyces were present (Graph no. 5). Kaye K. W.12 stated that the numbers of minor calyces were 4 to 12 (most often 8). Sykes and David ${ }^{13}$ found that the number of minor calyces varies from 5 to 20 (average 8 to 9). Similarly Harrison ${ }^{14}$ reported that there were 8 to 9 minor calyces in kidney. Hollinshead ${ }^{15}$ and Dyson M. ${ }^{16}$ claimed that there were 7 to 8 minor calyces. Ningthoujam D. D. et a ${ }^{17}$ found that the numbers of minor calyces were 8 to 18 .

\section{Major Calyces}

Fine and Keen ${ }^{18}$ reported the presence of two major calyces in majority of cases and also the presence of third major calyx in some cases. Ningthoujam D. D. et $\mathrm{al}^{17}$ reported that the number of major calyces varies from 2 to 3.

In present study the number of major calyces varies from 2 to 3 . Two major calyces were present in $60 \%$. (Graph no. 6).

\section{Conclusion}

The obtained data showed that there were numerous variations not only in the numbers of calyces of kidneys but also in the infundibular length and width. Developments in endourology, percutaneous nephrolithotomy and techniques for retrograde percutaneous nephrostomy have rekindled interest in the anatomy of the renal collecting system. To perform these procedures safely and efficiently it is essential to have a clear understanding of pelvicalyceal anatomy and its variations. Thus the in-depth knowledge of 
PR Wadekar et al. Study of variations in the pelvicalyceal system of kidney and its clinical importance.

pelvicalyceal anatomy will be of immense value to the clinicians of related specialties.

\section{References}

1. Howard M. Pollack. Clinical Urography- an Atlas and Textbook of urological imaging. Philadelphia, W B Saunders Co. 1990;1: 135-78.

2. Hanif MS, Toori MH, Sheikh MA. Detailed calyceal anatomy for endourology. Pakistan J. Med. Res. 2004; 43(4): 184-7.

3. Kupeli B, Tunc L, Acar C, et al. The impact of pelvicalyceal anatomical variations between the stonebearing and normal contralateral kidney on stone formation in adult patients with lower calyceal stones. Int. Braz. J. Urol. 2006; 32(3): 22-32.

4. Sun YB, Kim YH, Kwon CH. Anatomical factors that affect lower calyceal stone clearance after shock wave lithotripsy. Korean J. Urol. 1999; 40(11): 1440-4.

5. Gupta NP, Singh DV, Hemal AK, et al. Infundibulopelvic anatomy and clearance of inferior calyceal calculi with shock wave lithotripsy. The Journal of Urology. 2000; 163: $24-7$.

6. Madbouly K, Sheir KZ, Elsobky E. Impact of lower pole renal anatomy on stone clearance after shock wave lithotripsy: fact or fiction?. Journal of Urology. 2001;165: 1415-18.

7. Srivastava A, Zaman W, Singh V, et al. Efficacy of extracorporeal shock wave lithotripsy for solitary lower calyceal stone: a statistical model. B.J.U. International. 2004; 93: 364-8.
8. Sorensen CM, Chandhoke PS. Is lower pole calyceal anatomy predictive of extracorporeal shock wave lithotripsy success for primary lower pole kidney stone? Journal of Urology. 2002; 168: 2377-82.

9. Sampaio FJB, Aragao AHM. Inferior pole collecting system anatomy: it's probable role in extracorporeal shock wave lithotripsy. Journal of Urology. 1992; 147: $322-4$.

10. Li-ping X, Shi-fang S. Radiographic anatomical insight into mechanism of lower calyceal stone evacuation following ESWL. Journal of Zhejiang University Science. 2000; 1(3): 347-51.

11. Sabnis RB, Naik K, Patel SH, et al. Extracorporeal shock wave lithotripsy for lower calyceal stones: can clearance be predicted? British Journal of Urology. 1997; 80: 853-7.

12. Kaye KW. Renal anatomy for endourological stone removal. The Journal of Urology. 1983; 130: 647-8.

13. Syke D. The Morphology of renal lobulations and calyces, and their relationship to partial nephrectomy. Brit. J. Surg. 1964; 51(4): 294-304.

14. Cunningham's Textbook of Anatomy. $11^{\text {th }}$ edi. London, Oxford University Press. 1972: 503-56.

15. Anatomy for Surgeons. New York, A Hoeber-Harper Book. 1956;2: 540-2.

16. Gray’s Anatomy. 38 ${ }^{\text {th }}$ edi. Edinburgh, Churchill Livingstone. 1995:1813-45.

17. Ningthoujam DD, Chongtham RD, Sinam SS. Pelvicalyceal system in foetal and adult kidneys. J. Anat. Soc. India. 2005;54(1): 1-11.

18. Fine J, Keen EN. The arteries of the human kidney. $J$. Anat. 1966; 100(4): 881-94. 